\title{
Subchorionic hematoma and pregnancy outcomes in patients with threatened miscarriage
}

\author{
Sumaira Naz ${ }^{1}$, Sheikh Irfan², \\ Tahira Naru3 ${ }^{3}$ Ayesha Malik ${ }^{4}$
}

\begin{abstract}
Objective: To compare maternal and perinatal outcomes in patients with threatened miscarriage with or without subchorionic hematoma $(\mathrm{SCH})$ at a tertiary care hospital.

Methods: This retrospective cohort study was conducted at Aga Khan University Hospital. The study included 200 patients of $<20$ weeks singleton pregnancy with threatened miscarriage from January 2016 till December 2018. These patients were divided into two groups based on the presence (study group) or absence of subchorionic hematoma (control) on ultrasound imaging. Baseline demographic data, and obstetric outcomes were compared for the two groups.

Results: The incidence of subchorionic hematoma was observed to be $30.5 \%(61 / 200)$. Most of the patients of $\mathrm{SCH}$ and non $\mathrm{SCH}$ groups presented in first trimester. Age and $\mathrm{BMI}$ were similar for both groups however there were more multigravida patients in the $\mathrm{SCH}$ group (63\% versus $46.7 \%, \mathrm{P}=0.12)$. A higher number of patients in the $\mathrm{SCH}$ group ended up in spontaneous miscarriage in contrast to patients with no $\mathrm{SCH}(13 \%$ versus $6.1 \%, \mathrm{P}=0.07)$ and also had a greater proportion of small for gestational age (SGA) babies $(8.9 \%$ versus $3.9 \%$ ) though no statistical significance was observed. There were more preeclamptic patients in $\mathrm{SCH}$ group as compared to non $\mathrm{SCH}$ group $(4.8 \%$ versus $0.7 \%)$ and the trend was statistically significant $(\mathrm{P}=0.05)$. However, no significant correlation of hematoma size and adverse pregnancy outcomes was found in $\mathrm{SCH}$ group.

Conclusion: Our study shows that women with threatened miscarriage having $\mathrm{SCH}$ are at a higher risk of having preeclampsia and SGA and hence these pregnancies warrant greater surveillance.
\end{abstract}

KEYWORDS: Threatened Miscarriage, Subchorionic Hematoma, Small for gestational age, Preeclampsia.

How to cite this:

doi: https://doi.org/10.12669/pjms.38.3.4283

Naz S, Irfan S, Naru T, Malik A. Subchorionic hematoma and pregnancy outcomes in patients with threatened miscarriage. Pak J Med Sci. 2022;38(3):511-516. doi: https://doi.org/10.12669/pjms.38.3.4283

This is an Open Access article distributed under the terms of the Creative Commons Attribution License (http://creativecommons.org/licenses/by/3.0), which permits unrestricted use, distribution, and reproduction in any medium, provided the original work is properly cited.

1. Dr. Sumaira Naz, FCPS

2. Dr. Sheikh Irfan, MPH.

3. Dr. Tahira Naru, FAOG, MD.

4. Dr. Ayesha Malik, MRCOG.

1-4: Department of Obstetrics \& Gynecology,

Aga Khan University Hospital,

Karachi, Pakistan.

Correspondence:

Dr. Ayesha Malik, FCPS, MRCOG

Assistant Professor,

Aga Khan University Hospital,

Karachi, Pakistan.

Email: ayesha.malik@aku.edu

* Received for Publication:

* Revision Received:

* Accepted for Publication:
February 20, 2021

April 20, 2021

October 25, 2021

\section{INTRODUCTION}

Threatened miscarriage is the most common complication in the first half of pregnancy affecting $20-25 \%$ of women. ${ }^{1}$ Diagnosis of threatened miscarriage is established when there is a viable pregnancy with vaginal bleeding and a closed cervix. $^{2}$

Any woman who presents with threatened miscarriage, ultrasound imaging is performed to ascertain the viability, location of the placenta and the presence or absence of sub chorionic hematoma. Subchorionic hematoma $(\mathrm{SCH})$ is defined as a sonographically-detected, collection of 
blood between the chorion and the endometrium. Although, SCH may happen spontaneously, the exact aetiology is uncertain. They are believed to result from partial detachment of the chorionic membranes from the uterine wall. ${ }^{3}$ The other possible explanation could be affected trophoblast invasion and impaired change in spiral arteries at the time of implantation. The incidence of hematoma detected on ultrasound varies between $0.46-39.5 \%{ }^{4}$ Almost $20 \%$ of women that present with threatened miscarriage have a sub chorionic hematoma. ${ }^{5}$

Threatened miscarriage has been linked with increased risk of hypertensive disorders of pregnancy, preterm pre labor rupture of membranes (PPROM), spontaneous preterm labor, antepartum hemorrhage (APH), intra uterine growth retardation and Caesarean Section. ${ }^{2,6}$ Fetal loss is also described in about one quarter of threatened miscarriage cases especially from low socioeconomic background.? Some studies have mentioned $\mathrm{SCH}$ as a causal factor for adverse outcomes whereas other studies observed no association between $\mathrm{SCH}$ and affected maternal and perinatal outcomes. ${ }^{4,8,9}$ One metaanalysis demonstrated an increased risk of early and late pregnancy loss, placental abruption, and PPROM in patients with $\mathrm{SCH} \cdot{ }^{10}$ However, $\mathrm{Li} \mathrm{Q}$ et al. ${ }^{11}$ in a recent meta-analysis identified increased risk of miscarriage with $\mathrm{SCH}$ but found no effect on premature delivery rate and delivery mode. Similarly, controversies exist regarding the correlation of SCH volume, and the simultaneous presence of vaginal bleeding with adverse obstetric outcomes. ${ }^{8}$ Pedersen and Mantoni ${ }^{12}$ stated that presence of large hematomas does not affect pregnancy outcomes whereas Bennett et al. $^{13}$ highlighted that factors like maternal age, size of the hematoma, and gestational age affects fetal outcome.

These conflicting results emphasized the need to consider whether it's the occurrence of first trimester bleed or the presence of subchorionic hematoma that augments the risk for adverse outcomes in threatened miscarriage. Furthermore, local data is deficient to evaluate significance of $\mathrm{SCH}$ in these patients. In our setting, a number of pregnant patients present with vaginal bleeding during early pregnancy and diagnosed to have threatened miscarriage. This study will help to comprehend any added risks to patients with $\mathrm{SCH}$ and threatened miscarriage and provide an insight to the care givers to counsel these patients for anticipated adverse outcomes.

\section{METHODS}

This retrospective cohort study was conducted in Obstetrics \& Gynecology department at Aga Khan University Hospital, Karachi, Pakistan. After attaining exemption from ethical review board (ERC\# 2019-1837-4975, September $5^{\text {th }}$, 2019), medical records of all patients were reviewed who were diagnosed with threatened miscarriage $(n=286)$ during first trimester or early second trimester and admitted from January 2016 to December 2018. Data was retrieved from hospital inpatient database using coding for threatened miscarriage and subchorionic hematoma. The inclusion criteria were singleton alive intrauterine pregnancy with gestational age $<20$ weeks and bleeding per vaginum (threatened miscarriage) with or without SCH. Patients were excluded if having diagnosis of miscarriage other than threatened miscarriage, absent fetal cardiac activity, gestational age $\geq 20$ weeks, multiple pregnancy, known hypertensive status, any bleeding disorders, cases of detected congenital anomalies, prior history of recurrent miscarriages and preterm labor. Those who lost to follow up for delivery were also excluded from the selected patients.

There were 200 patients who met inclusion criteria. These patients were then divided into two groups based on the presence (study group) or absence of subchorionic hematoma (control group) on ultrasound imaging of pelvis. The patients who had threatened miscarriage without sub chorionic hematoma were recruited as control group $(n=139)$ and the patients with $\mathrm{SCH}(\mathrm{n}=61)$ were included in study group. A structured proforma was used to gather data regarding demographics, pregnancy course, ultrasound information for $\mathrm{SCH}$ and maternal and perinatal outcomes. Both groups were compared for pregnancy outcomes including miscarriage, APH including abruptio placentae\& placenta previa, $\mathrm{PIH}$, preeclampsia, intrauterine fetal demise, preterm labor, PPROM and mode of delivery. In patients whose pregnancies continued and resulted in delivery, term or preterm status, birth weight, Apgar score, NICU admission and neonatal death were also compared between the two groups. SCH patients were also evaluated for correlation of hematoma size $(<5 \mathrm{~cm}$ or $>5 \mathrm{~cm})$ with adverse pregnancy outcomes.

Statistical Analysis: All the data was entered and analyzed in SPSS version 19.0. Categorical variables in the statistical analysis were assessed 
by chi square analysis or two-tailed Fisher exact test in cases of small- expected cell frequencies. Differences in continuous variables were evaluated by a two-tailed Student $t$ test. P-values less than 0.05 was considered statistically significant and the $95 \%$ confidence intervals was calculated.

\section{RESULTS}

In this study, a total of 200 pregnant patients with threatened miscarriage were recruited. Out of these, sixty-one patients had sonographic evidence of $\mathrm{SCH}$ while 139 patients were without hematoma. The incidence of SCH was found to be $30.5 \%(61 / 200)$ and in $78 \%$ patients' size of hematoma was less than $5 \mathrm{~cm}$ whereas $21 \%$ had hematoma more than $5 \mathrm{~cm}$.

Demographic features of participants with and without SCH are shown in Table-I. The frequency of different age group intervals was similar for patients of both groups. In $\mathrm{SCH}$ group, 39\% of patients were aged between 25 to 29 years versus $41 \%$ patients in non SCH group. Similarly, in SCH group $16 \%$ of all patients were above 35 years of age while $15 \%$ were 35 years of age. There was more multigravida in the SCH group (63\%) compared to the non-hematoma group $(46.7 \%)$. However, this difference did not reach statistical significance $(p=0.12)$. Most of the patients presented in first trimester as compared to second trimester. This trend was similar both for $\mathrm{SCH}(67 \%$ versus $32 \%)$ and non SCH group $(64 \%$ versus $36 \%$ ). In both the groups, the frequency of overweight and obese women was similar.

About $13 \%$ patients in $\mathrm{SCH}$ group ended up having a miscarriage. Table-II While in comparison, the non $\mathrm{SCH}$ group had $6.1 \%$ of index pregnancies ending in miscarriage. There was a trend towards statistical significance (0.07). The frequency of preterm labor was broadly comparable in both the groups with a non-significant $\mathrm{p}$-value of 0.4 . In SCH group, $82 \%$ of participants presented with preterm labor compared to $76 \%$ patients in the other group. A similar comparable trend was seen for PPROM among both the group with $p$ value of 0.31 . In each group one patient had APH due to abruption.

There were smaller for gestational age (SGA) fetuses in the $\mathrm{SCH}$ group $(8.9 \%)$ compared to $3.9 \%$ in the non-hematoma group. Though this could not reach statistical significance due to small numbers in each cell. The number of preeclamptic patients in the hematoma group was higher $(4.8 \%)$ compared to the other group $(0.7 \%)$ and the trend was statistically significant $(\mathrm{p}=0.05)$. The frequency of cesarean section was similar in both the groups; with $48.8 \%$ of patients in the $\mathrm{SCH}$ group ending up in lower segment cesarean section (LSCS) while the frequency of operative delivery was $52.8 \%$ in the non $\mathrm{SCH}$ group (Table-II).

Neonatal outcomes of the two groups are shown in Table-III. The frequency of normal birth

Table-I: Clinical characteristics of study participants among study and control groups (n=200).

\begin{tabular}{|c|c|c|c|}
\hline Demographics & $\begin{array}{l}{ }^{*} \text { TM without SCH } \\
\text { (Control Group) }\end{array}$ & $\begin{array}{l}\text { TM with SCH } \\
\text { (Study Group) }\end{array}$ & $\begin{array}{l}\text { PValue } \\
(p<0.05)\end{array}$ \\
\hline \multicolumn{4}{|l|}{ Age in years } \\
\hline $18-24$ & $26(18.7 \%)$ & $11(18 \%)$ & \multirow{4}{*}{0.991} \\
\hline $25-29$ & $57(41 \%)$ & $24(39 \%)$ & \\
\hline $30-34$ & $35(25 \%)$ & $16(26 \%)$ & \\
\hline$>35$ & $21(15 \%)$ & $10(16.3 \%)$ & \\
\hline \multicolumn{4}{|l|}{ Parity } \\
\hline Primigravida & $74(53.2 \%)$ & $22(36 \%)$ & \multirow[t]{2}{*}{0.012} \\
\hline Multigravida & $65(46.7 \%)$ & $39(63 \%)$ & \\
\hline \multicolumn{4}{|l|}{ Gestational Age } \\
\hline First trimester (1-13 weeks) & $89(64 \%)$ & $41(67.2 \%)$ & \multirow[t]{2}{*}{0.748} \\
\hline Second trimester (14 -26weeks) & $50(35.9 \%)$ & $20(32.7 \%)$ & \\
\hline \multicolumn{4}{|l|}{ BMI } \\
\hline$<18$ & $6(4.3 \%)$ & $2(3 \%)$ & \multirow{5}{*}{0.757} \\
\hline $18-24.9$ & $42(31 \%)$ & $23(37.7 \%)$ & \\
\hline $25-29.9$ & $58(41 \%)$ & $20(32 \%)$ & \\
\hline $30-35$ & $28(20.1 \%)$ & $14(22.9 \%)$ & \\
\hline$>35$ & $5(3 \%)$ & $2(3.2 \%)$ & \\
\hline
\end{tabular}

*TM: Threatened Miscarriage SCH: Subchorionic Hematoma P Value: significant if < 0.05. 
Sumaira Naz et al.

Table-II: Maternal outcomes in between study and control groups $(n=200)$.

\begin{tabular}{|c|c|c|c|}
\hline Obstetric Outcome & $\begin{array}{l}\text { TM without SCH } \\
\text { (Control Group) }\end{array}$ & $\begin{array}{l}\text { TM with SCH } \\
\text { (Study Group) }\end{array}$ & $\begin{array}{c}P \text { value } \\
(P<0.05)\end{array}$ \\
\hline \multicolumn{4}{|l|}{ Miscarriage } \\
\hline Yes & $8(6.1 \%)$ & $8(13 \%)$ & \multirow[t]{2}{*}{0.07} \\
\hline No & $131(93.8 \%)$ & $53(86.8 \%)$ & \\
\hline \multicolumn{4}{|l|}{ Preterm Labor } \\
\hline No & $106(76.2 \%)$ & $50(81.96 \%)$ & \multirow[t]{2}{*}{0.459} \\
\hline Yes & $33(23.7 \%)$ & $11(18 \%)$ & \\
\hline \multicolumn{4}{|l|}{ PPROM } \\
\hline No & $122(87.7 \%)$ & $57(93.4 \%)$ & \multirow[t]{2}{*}{0.318} \\
\hline Yes & $17(12.2 \%)$ & $4(6.5 \%)$ & \\
\hline \multicolumn{4}{|l|}{ Antepartum Hemorrhage } \\
\hline No & $138(99 \%)$ & $60(98.3 \%)$ & \multirow[t]{2}{*}{0.518} \\
\hline Yes & $1(0.7 \%)$ & $1(1.64 \%)$ & \\
\hline \multicolumn{4}{|l|}{$S G A$} \\
\hline No & $121(96 \%)$ & $42(91.3 \%)$ & \multirow[t]{2}{*}{0.251} \\
\hline Yes & $5(3.9 \%)$ & $4(8.9 \%)$ & \\
\hline \multicolumn{4}{|l|}{ Preeclampsia } \\
\hline No & $138(99.2 \%)$ & $58(95 \%)$ & \multirow[t]{2}{*}{0.05} \\
\hline Yes & $1(0.7 \%)$ & $3(4.8 \%)$ & \\
\hline \multicolumn{4}{|l|}{ Mode of Delivery } \\
\hline SVD & $51(40.8 \%)$ & $23(51 \%)$ & \multirow{3}{*}{0.151} \\
\hline LSCS & $66(52.8 \%)$ & $22(48.8 \%)$ & \\
\hline Assisted Vaginal Delivery & $08(6.4 \%)$ & 0 & \\
\hline
\end{tabular}

weight babies was similar for both the groups. The frequency of low birth weight in the SCH and non $\mathrm{SCH}$ was $15.6 \%$ and $21.6 \%$ respectively. There was no difference observed in the 5-minute APGAR score of neonates for both the groups. However, $11 \%$ of neonates from the $\mathrm{SCH}$ group needed NICU admission versus $8 \%$ of newborns in the non $\mathrm{SCH}$ group.

\section{DISCUSSION}

Our study results showed $\mathrm{SCH}$ in $30 \%$ of patients with threatened miscarriage and this

Table-III: Neonatal outcomes in between study and control groups $(n=200)$.

\begin{tabular}{lccc}
\hline Neonatal Outcome & $\begin{array}{c}\text { TM without SCH } \\
\text { (Control Group) }\end{array}$ & $\begin{array}{c}\text { T M with SCH } \\
\text { (Study Group) }\end{array}$ & $\begin{array}{c}\text { P value } \\
\text { (P value <0.05) }\end{array}$ \\
\hline Birth Wt. $($ Kg) & $27(21.6 \%)$ & $07(15.5 \%)$ & \\
$<2.5$ & $95(76 \%)$ & $34(75.5 \%)$ & 0.136 \\
$2.5-3.5$ & $3(2.4 \%)$ & $4(8.8 \%)$ & \\
$>3.5$ & & & \\
Apgar Scores & $1(0.8 \%)$ & 0 & 0.674 \\
3.00 & 0 & $3(6 \%)$ & \\
7.00 & $2(1.63 \%)$ & $1(2 \%)$ & \\
8.00 & $119(97.5 \%)$ & $44(91.6 \%)$ & 0.548 \\
9.00 & & & \\
NICU Admission & $114(91.0 \%)$ & $40(88.8 \%)$ & \\
No & $10(8 \%)$ & $05(11.1 \%)$ & \\
Yes &
\end{tabular}


was comparable to $43 \%$ reported by Dongol A et al. ${ }^{14}$ The salient findings of our study were that there were more multigravida patients in the $\mathrm{SCH}$ group. In addition, a higher number of patients in the hematoma group ended up in spontaneous miscarriage in contrast to patients with no $\mathrm{SCH}$ and also had a greater proportion of SGA babies and pre-eclampsia compared to the group with only threatened miscarriage.

Study by Peixoto et al., ${ }^{15}$ also found parity to be higher with sub chorionic hematoma. Similarly, a polish study ${ }^{16}$ also found a higher proportion of multipara women in the hematoma group. This may be due to the multigravida group having a greater proportion of women with advance maternal age, which is also a risk factor for $\mathrm{SCH} .{ }^{17}$

Our results showed a greater proportion of women in the hematoma group to eventually have spontaneous miscarriage compared to the nonhematoma group. This finding is consistent with previous studies. Tuuli et al. ${ }^{10}$ pooled the results of five studies and concluded that women with $\mathrm{SCH}$ have a two-fold increase risk of spontaneous miscarriage in contrast to women with only threatened miscarriage. Similarly, a local study highlighted strong association of $\mathrm{SCH}$ with miscarriage $(37.9 \%$ vs. $9.7 \%$, P-value $<0.05)$ as compared to non $\mathrm{SCH}$ group..$^{18}$ Our findings support the postulated hypothesis that the mechanical effect of $\mathrm{SCH}$ can cause miscarriage by causing detachment of the sac from the endometrium. ${ }^{6}$

Our study showed that greater proportion of women in the hematoma group had SGA fetuses compared to their non-hematoma counterparts whereas, previous studies regarding SGA as an outcome have conflicting results. Our findings are consistent with a study by Ozkaya et al. ${ }^{19}$, that described an increased risk of SGA in the hematoma group. Similarly, a study done by Nagy et al. which had 187 patients with $\mathrm{SCH}$, and 6488 controls showed SGA was significantly higher in the SCH group $(7 \%$ versus $3 \%[p=0.002]) .{ }^{20}$ In contrast, a Russian study by Bushtyreva et al., which included 115 women with SCH, and 79 controls did not find any significant association between SGA and $\mathrm{SCH} .{ }^{9}$

Our study did not show any statistical increase in the number of preterm deliveries in the $\mathrm{SCH}$ group. Existing literature shows conflicting evidence with regards to association of $\mathrm{SCH}$ and preterm delivery. A study done by Peixoto $\mathrm{AB}$ et $\mathrm{al} .{ }^{15}$, demonstrated an equal rate of $16 \%$ preterm deliveries for both the $\mathrm{SCH}$ and non $\mathrm{SCH}$ group. Similarly, a study conducted by Irina $\mathrm{O}$
Bushtyreva did not find any correlation between $\mathrm{SCH}$ diagnosed in first trimester and increase rate of preterm delivery. ${ }^{9}$ However, there also exists contrary evidence. A retrospective cohort study conducted by Normal et al..$^{21}$ showed an increase risk of preterm delivery less than 34 weeks in patients diagnosed with subchorionic hematoma before 22 weeks: $4.2 \%$ compared with $2.7 \%$, (OR 1.7, 95\% CI 1.3-2.4, P.01).

A significant association between preeclampsia and $\mathrm{SCH}$ was observed in our study. This is consistent with the outcomes reported by Nagy et al. $^{20}$ that women with $\mathrm{SCH}$ were at a fourfold higher risk of preeclampsia compared to women in the control group (RR 4.0,95\% CI $(2.4,6.7))$. A local study has also described similar association. ${ }^{18}$ However, our results do contradict with few studies. The retrospective cohort study done by Araujo et al. ${ }^{15}$, showed no association between subchorionic hematoma and hypertension in pregnancy. The study done by Hashem et al. ${ }^{22}$ in India did show an association between $\mathrm{SCH}$ and SGA but not with preeclampsia. Our study has shown an increase frequency of both SGA and preeclampsia in the $\mathrm{SCH}$ group compared to the control group..$^{10} \mathrm{To}$ explain these findings, it is important to discuss the underlying mechanism.

Though the phenomenon is incompletely understood, one possible explanation is the occurrence of premature perfusion of the intervillous space due to the presence of $\mathrm{SCH}$ prior to the completion of placental adaptation to cope with oxidative stress. ${ }^{10,23}$ Other possible explanations could be shallow trophoblastic invasion with inadequate angiogenesis causing friable blood vessels. These fragile blood vessels predispose to subchorionic hemorrhage. ${ }^{11,23}$ Furthermore, we found no significant correlation of hematoma size with adverse pregnancy outcomes. This is consistent with the findings reported by Naqvi M et al. ${ }^{24}$

Strength of our study: The strength of our study is that to our knowledge there are limited studies from South Asia addressing this issue and only one study from Pakistan has evaluated association of $\mathrm{SCH}$ with adverse pregnancy outcomes. ${ }^{18}$ Other local studies have addressed management ${ }^{25}$ and outcomes of threatened miscarriage ${ }^{6}$ without $\mathrm{SCH}$ or focused on the sonographic features of $\mathrm{SCH}$.

Limitations of our study: It includes its retrospective nature and relatively small sample size. The small study sample resulted in showing results that 
were not statistically significant though they were clinically important.

A number of studies have postulated defective placentation as underlying mechanisms of $\mathrm{SCH} .{ }^{2}$ It is interesting to note that we also have found an increase frequency of placental mediated diseases in this group, that is, Preeclampsia and SGA. This opens up the opportunity for screening for Preeclampsia in first trimester using Uterine artery Dopplers and possible use of Aspirin later if the per vaginal bleeding has settled.

\section{CONCLUSION}

Our study shows that women with threatened miscarriage having $\mathrm{SCH}$ are at a higher risk of having preeclampsia and SGA and hence these pregnancies warrant greater surveillance.

\section{Grant Support \& Financial Disclosures: None.}

\section{REFERENCES}

1. National Guideline Alliance (UK). Ectopic pregnancy and miscarriage: Diagnosis and initial management. London: National Institute for Health and Care Excellence (UK). April 2019 Available at: www.nice.org.uk/guidance/ng126 Accessed on Feb. 12,2021

2. Saraswat L, Bhattacharya S, Maheshwari A, Bhattacharya S. Maternal and perinatal outcome in women with threatened miscarriage in the first trimester: a systematic review. Br J Obstet Gynecol. 2010;117(3):245-257. doi: 10.1111/j.14710528.2009. 02427.x

3. Sukur YE, Goc G, Kose O, Acmaz G, Ozmen B, Atabekoglu CS, Koc A, Soylemez F. The effects of subchorionic hematoma on pregnancy outcome in patients with threatened abortion. J Turk Ger Gynecol Assoc. 2014;15(4):239-242. doi: 10.5152/ jtgga.2014.14170

4. Xiang L, Wei Z, Cao Y. Symptoms of an intrauterine hematoma associated with pregnancy complications: a systematic review. PLoS One. 2014;9(11):e111676. doi: 10.1371/journal. pone. 0111676

5. Nyberg DA, Cyr DR, Mack LA, Wilson DA, Shuman WP. Sonographic spectrum of placental abruption. Am J Roentgenol 1987;148(1):161-164. doi: 10.221/ajr.148.1.161

6. Naurin R, Tahseen S, Naurin R. Maternal Outcome in Women with Threatened Miscarriage. Pak J Med Health Sci. 2016;1(10):273-275.

7. Dede FS, UL ucay U, Kose MF, Dede H, Dilbaz S. Fetal loss in threatened abortion after demonstration of fetal cardiac activity in a low socioeconomic population. J Obstet Gynecol. 2010;30(6):622-625. doi: 10.3109/01443615.2010.489164

8. Kyser KL. Meta-analysis of subchorionic hemorrhage and adverse pregnancy outcomes. Proc Obstet Gynecol. 2012;2(4):1-9. doi: $10.17077 / 2154-4751.1137$

9. Bushtyreva IO, Kuznetsova NB, Barinova VV, Kovaleva AV Dmitrieva MP. Pregnancy outcomes in pregnant women with subchorionic hematoma. Inter J Biomed. 2015;5(3):137-140.

10. Tuuli MG, Norman SM, Odibo AO, Macones GA, Cahill AG. Perinatal outcomes in women with subchorionic hematoma: a systematic review and meta-analysis. Obstet Gynecol 2011;117(5):1205-1212. doi: 10.1097/aog.0b013e31821568de

11. Li Q, Zhu J, Hua K. Effects of subchorionic hematoma on pregnancy outcome: a meta-analysis. Zhonghua yi xue za zhi. 2016;96(17):1383-1385. doi: $10.3760 / \mathrm{cma}$.j.is sn.0376-2491.2016.17.017
12. Pedersen JF, Mantoni M. Prevalence, and significance of subchorionic hemorrhage in threatened abortion: a sonographic study. Am J Roentgenol. 1990;154(3):535-537. doi: 10.2214/ajr.154.3.2106217

13. Ben-Haroush A, Yogev Y, Mashiach R, Meizner I. Pregnancy outcome of threatened abortion with subchorionic hematoma: possible benefit of bed rest? Isr Med Assoc J. 2003;5(6):422-424

14. Dongol A, Mool S, Tiwari P. Outcome of pregnancy complicated by threatened abortion. Kathmandu Univ Med J. 2011;9(1):41-44. doi: 10.3126/kumj. V 9i1.6261

15. Peixoto $A B$, Caldas $T$, Petrini $C G$, Romero ACP, Júnior LEB, Martins WP, et al. The impact of first-trimester intrauterine hematoma on adverse perinatal outcomes. Ultrasonography. 2018;37(4):330-336. doi: 10.14366/usg.18006

16. Biesiada L, Krekora M, Krasomski G. Subchorionic hematoma as a risk factor of pregnancy and delivery in women with threatening abortion. Ginekol Pol. 2010;81(12).902-906.

17. Cohain JS, Buxbaum RE, Mankuta D. Spontaneous first trimester miscarriage rates per woman among parous women with 1 or more pregnancies of 24 weeks or more. BMC Pregnancy Childbirth. 2017;17(1):437. doi: 10.1186/s12884-017-1620-1

18. Hanif S, Shabir N, Zubair M, Pirzada H, Zia MS. The Effects of Subchorionic Hematoma on Pregnancy Outcome in Patients with Threatened abortion. J Soc Obstet Gynecol Pak. 2019;9(3):186-191.

19. Ozkaya E, Altay M, Gelisen O. Significance of subchorionic haemorrhage and pregnancy outcome in threatened miscarriage to predict miscarriage, pre-term labour and intrauterine growth restriction. J Obstet Gynecol. 2011;31(3):210-212. doi: 1 0.3109/01443615.2010.545899

20. Nagy S, Bush M, Stone J, Lapinski RH, Gardó S. Clinical significance of subchorionic and retroplacental hematomas detected in the first trimester of pregnancy. Obstet Gynecol. 2003;102(1):94-100. doi: 10.1016/s0029-7844(03)00403-4

21. Norman SM, Odibo AO, Macones GA, Dicke JM,Crane JP, Cahill AG.Ultrasound-detected subchorionic hemorrhage and the obstetric implications. Obstet Gynecol. 2010;116(2):311-315. doi: 10.1097/AOG.0b013e3181e90170

22. Hashem A, Sarsam SD. The impact of incidental ultrasound finding of subchorionic and retroplacental hematoma in early pregnancy. J Obstet Gynecol India. 2019;69(1):43-49. doi: 10.1007/s13224-017-1072-6

23. Jauniaux E, Van Oppenraaij RH, Burton GJ. Obstetric outcome after early placental complications. Curr Opin Obstet Gynecol. 2010;22(6):452-457. doi: 10.1097/GCO.0b013e3283404e44

24. Naqvi M, Naert MN, Khadraoui H, Rodriguez AM, Namath AG, Ali M, et al. Subchorionic hematomas and adverse pregnancy outcomes among twin Pregnancies. Am J Perinatol. 2019. doi: $10.1055 / \mathrm{s}-0039-3401852$

25. Parveen R, Khakwani M, Tabassum S, Masood S. Oral versus vaginal micronized progesterone for the treatment of threatened miscarriage. Pak J Med Sci. 2021;37(3):628-632. doi: 10.12669 /pjms.37.3.3700

\section{Author`s Contribution:}

SNAZ conceived, drafting, data collection, manuscript writing, responsible for data integrity and authenticity.

ISH did statistical analysis and review of manuscript.

TNAR reviewed and final approval of manuscript. AM contributed to designing, results analysis, manuscript writing and editing. 